\title{
Metronomic Antiangiogenic Therapy with Capecitabine and Celecoxib in Advanced Tumor Patients - Results of a Phase II Study
}

\author{
Simone Steinbild Jann Arends Michael Medinger Brigitte Häring Annette Frost \\ Joachim Drevs Clemens Unger Ralph Strecker Jürgen Hennig Klaus Mross
}

Tumor Biology Center at the Albert Ludwigs University Freiburg and MR Development and Application Center of the University Hospital Freiburg, Germany

\section{Key Words}

Metronomic therapy - Capecitabine - Celecoxib . Antiangiogenic therapy

\section{Summary}

Background: Combined therapy of continuous low dose capecitabine and high dose celecoxib targeting angiogenesis was used in a phase II trial to treat advanced cancer patients. Dynamic contrast-enhanced magnetic resonance imaging (DCE-MRI) was used to monitor antiangiogenic effects. Material and Methods: 37 Patients (21 men, 16 women), mean age 60 years, with advanced and progressive cancer of various tumor types were included. Therapy consisted of $2 \times 500 \mathrm{mg}$ oral capecitabine/day and $2 \times 400 \mathrm{mg}$ oral celecoxib/day continuously until progression of disease. To monitor antiangiogenic effects, DCE-MRI measurements were performed at baseline, after 1 month, and after 3 months of therapy. Tumor assessment was performed according to RECIST criteria, toxicity was evaluated according to the CTC version 2.0 catalogue. Results: Therapy was well tolerated without grade 3 and 4 toxicities. The mean number of treatment cycles was 4 (range: 1-15+). Disease stabilization after 3 cycles was seen in 11 patients. 6 patients were stable over long periods. The mean number of treatment cycles in this group was 10 (range: 7-15+). DCE-MRI demonstrated a reduction of tumor vessel permeability and blood flow in patients who reached stable disease or some minor regression. Conclusion: Continuous dosing of the combination of capecitabine and celecoxib was well tolerated, produced antiangiogenic effects, and has antitumor activity. Patients with rapid progression did not benefit.
Schlüsselwörter

Metronomische Therapie - Capecitabin - Celecoxib · Antiangiogene Therapie

\section{Zusammenfassung}

Hintergrund: Niedrig dosiertes Capecitabin in Kombination mit hoch dosiertem Celecoxib wurde als metronomische, antiangiogene Therapie bei fortgeschrittenen Tumorpatienten im Rahmen einer Phase-II-Studie eingesetzt. Das Monitoring antiangiogener Effekte umfasste Untersuchungen mittels dynamischer-kontrastmittelverstärkter (DCE)-MRI. Material und Methoden: $37 \mathrm{~Pa}$ tienten (21 Männer, 16 Frauen) mit einem mittleren Alter von 60 Jahren und progressivem Tumorwachstum wurden behandelt. Die Patienten wurden mit $2 \times 500 \mathrm{mg} \mathrm{Ca}-$ pecitabin und $2 \times 400 \mathrm{mg}$ Celecoxib po/Tag kontinuierlich bis zum Nachweis einer Tumorprogression behandelt. Für das Monitoring antiangiogener Effekte wurde die DCE-MRI-Untersuchungstechnik angewandt. Das Tumoransprechen wurde entsprechend RECIST-Kriterien ausgewertet, die Nebenwirkungen nach dem CTC-Katalog Version 2,0. Ergebnisse: Die Therapie wurde gut toleriert ohne schwerwiegende Toxizitäten Grad 3 und 4. Die mittlere Zyklusanzahl betrug 4 (von 1-15+). Krankheitsstabilisierung nach 3 Monaten trat bei 11 Patienten auf. Bei 6 Patienten wurden lang anhaltende stabile Krankheitsphasen induziert mit einer mittleren Anzahl von $10 \mathrm{Zy}$ klen (7-15+). Die DCE-MRI-Untersuchung zeigte eine Reduktion der Tumorgefäßpermeabilität und des Blutflusses bei den Patienten, die eine stabile Krankheitsphase erreichten. Schlussfolgerung: Die Kombination Capecitabin und Celecoxib ist gut verträglich, antiangiogen und zeigte antitumorale Effekte. Patienten mit einer schnellen Progression bei Aufnahme in die Studie profitierten nicht.

\begin{tabular}{ll}
\hline KARGER & @ 2007 S. Karger GmbH, Freiburg \\
$\begin{array}{ll}\text { Fax }+497614520714 & \text { Accessible online at: } \\
\text { E-mail Information@Karger.de } \\
\text { www.karger.com }\end{array}$ & www.karger.com/onk
\end{tabular}




\section{Introduction}

Cytotoxic drugs affect proliferating cancer cells as well as normal cells such as bone marrow, intestinal mucosa, or hair follicle cells. Effects include damage to the cells of the tumor microenvironment, in particular the epithelial cells (ECs) of the growing tumor vasculature. In comparison to myocytes, fibroblasts and tumor cells (TCs), ECs are highly vulnerable to very low anthracycline concentrations [1]. Cytotoxic drugs usually are administered at doses close to the maximum tolerated dose (MTD), targeting the malignant TC. MTD-based chemotherapy needs longer intervals between treatment cycles to allow recovery of healthy tissues. Alternatively, it has been proposed to use conventional cytotoxic chemotherapeutics to target tumor angiogenesis [2]. This approach is not invalidated by the fact that a monoclonal antibody as well as tyrosine kinase inhibitors interfering with the vascular endothelial growth factor (VEGF)-VEGF receptor system are currently available [3].

The basics of tumor neo-angiogenesis and tumor growth [4] have been established, and there is growing evidence that old cytotoxic drugs can be used to target the tumor vasculature via ECs. Only a few clinical trials with metronomic (i.e. daily dosing) schedules have been published, all of them were phase II or pilot studies. In 1999, several publications showed in model systems that the camptothecins topotecan [5] and irinotecan [6] as well as vinblastin [7] and a purine analogue [8] featured antiangiogenic properties when used at very low concentrations. In 2000, a combination of metronomic chemotherapy with a targeted antiangiogenic drug resulted in a remarkably prolonged survival of mice bearing neuroblastomas [9]. In 2006, a clinical study using a combined biodifferentiating and antiangiogenic oral metronomic therapy in children with relapsed solid tumors showed feasibility and efficacy. These results underline the potential of metronomic anticancer therapies $[10,11]$. Continuous chemotherapy administration is daily practice in several chemotherapy combinations (e.g. epidoxorubicin, cisplatin, 5-fluorouracil (5-FU)) but generally with dosages near the MTD to target the TC itself. These schedules contrast with the characteristics of a metronomic low-dose antiangiogenic therapy concept. The value of such low dose cytotoxic concepts using antiangiogenic daily schedules to target the EC remains to be fully assessed.

Besides the classical cytostatic drugs, there are several other approved drugs with antiangiogenic properties. Rapamycin is a bacterial macrolide that forms a complex with the FK-binding protein (FKBP-12) that binds with high affinity to the mammalian target of rapamycin (mTOR). Rapamycin inhibits primary and metastatic tumor growth by interfering with angiogenesis and the vascular endothelial growth factor $[12,13]$. Peroxisome proliferator activator receptors (PPAR) are members of a superfamily of nuclear hormone receptors. Drugs that inhibit this receptor (PPAR $\gamma$ agonists) which have been approved for the treatment of diabetes mellitus also ex- hibit antiangiogenic effects. PPAR $\gamma$ is highly expressed in the tumor endothelium, and interfering drugs like rosiglitazone, troglitazone, and pioglitazone result in inhibition of TC growth $[14,15]$. In addition, the statins are interesting, because, for these drugs, antitumor properties have been described such as induction of growth arrest and apoptosis, inhibition of metastasis, and inhibition of angiogenesis [16]. Experimental studies have shown that cyclooxygenase-2 (COX-2) is involved in tumor development and progression. Selective inhibitors of COX-2, the coxibs, block tumor growth by different mechanisms, displaying antiangiogenic and proapoptotic effects [17-19]. Surprisingly, not all anticancer effects of selective COX-2 inhibitors are COX-2 dependent, but some are COX-2-independent [20]. A pivotal study demonstrated that celecoxib suppresses adenomatous polyps and causes regression of existing polyps in patients with familial adenomatous polyposis [21]. In 1999, the FDA approved celecoxib as a preventive therapy at a suggested dose of 400 $\mathrm{mg}$ twice daily. Combinations of COX-2 inhibitors with classical cytotoxics showed promising results suggesting additional or synergistic anticancer effects in non-small cell lung cancer and colorectal cancer $[22,23]$. Metronomic schedules with cytotoxic drugs have limitations since not all drugs are available for oral application. Cytotoxic drugs that may be taken orally were tested with respect to their inhibitory effects on ECs and TCs.

All tested drugs were more active against the ECs in comparison to TCs, with much lower inhibitory concentrations $\left(\mathrm{IC}_{50}\right)$ for ECs $\left(4.03 \times 10^{-6}-6.16 \times 10^{-14} \mathrm{M}\right)$ than TCs $\left(7.44 \times 10^{-2}-1.9\right.$ $\left.\times 10^{-11} \mathrm{M}\right)$. In general, ECs were found to be 5-100 times more sensitive than TCs as shown for methotrexate, vinblastin, cyclophosphamide, paclitaxel, docetaxel, 5-FU, doxorubicin, idarubicin, and vepesid [24, 26, 27].

Thymidine phosphorylase (TP) is induced in the tumor microenvironment in stromal cells. Angiogenesis is promoted and apoptosis is inhibited by TP which may explain why tumors that overexpress TP have an unfavorable prognosis [26]. TP is also present in proliferating ECs which are important for the vascularization of tumors [28]. Capecitabine is an oral fluoropyrimidine carbamate, designed to generate 5-FU preferentially in cells with a high expression of TP [29]. Thus, these findings provided the rationale for investigating the combination of capecitabin and celecoxib in a phase II clinical study in patients with advanced tumors of different origin. Antiangiogenic effects were monitored by dynamic contrastenhanced magnetic resonance imaging (DCE-MRI) technique, which is currently the most reliable method for this purpose [30].

\section{Material and Methods}

\section{Patient Selection}

Patients older than 18 years with a histological or cytological diagnosis of locally advanced or metastatic tumor were eligible. All patients had 
Table 1. Patient characteristic

\begin{tabular}{lc}
\hline Characteristics & Patients, $\mathrm{n}$ \\
\hline Median age, years (range) & $60(32-78)$ \\
Eligible patients & \\
Male & 19 \\
Female & 16 \\
Disease status & \\
Locally advanced & 0 \\
Metastatic & 35 \\
Tumor types & \\
Colorectal cancer & 12 \\
Renal cell cancer & 10 \\
Gallbladder cancer & 2 \\
Cholangiocellular carcinoma & 2 \\
Pancreatic cancer & 3 \\
Other solid tumors & 8 \\
ECOG performance status & \\
0 & 11 \\
1 & 20 \\
2 & 4 \\
Palliative cytotoxic pretreatments, $\mathrm{n}$ & \\
0 & 3 \\
1 & 7 \\
2 & 8 \\
3 & 6 \\
4 & 5 \\
5 & 4 \\
7 & 2 \\
\hline
\end{tabular}

to have confirmed progressive disease (PD) after 1 (or more if available) standard palliative therapy. All patients were required to have recovered from any prior chemotherapy, radiotherapy, or surgery procedure before study entry. The presence of measurable disease, adequate hematologic, cardiovascular, renal, and hepatic function was mandatory. Patients with unstable cardiovascular disease, active infection, active gastric/duodenal ulcer, necessary treatment with nonsteroidal anti-inflammatory drugs, corticoids, fluconazole, lithium, or oral anticoagulation were considered ineligible. The protocol was reviewed and approved by the institutional ethical committee, and informed consent was obtained from all patients.

\section{Study Evaluation and Treatment}

Baseline evaluation included clinical examination, biochemical and hematological tests, chest X-ray, ultrasound, and MRI examination including a DCE-MRI scan. A region-of-interest (ROI)-based analysis was performed on the DCE-MRI data with pharmacodynamic modeling applying the Tofts model. The region of interest was mainly a metastatic lesion but could also be the primary tumor, depending on the best assumption for a reliable measurement baseline and for follow-up. The resulting parameter is the transfer constant $\mathrm{K}^{\text {trans }}$ related to blood flow and permeability. CT scans were only performed if ultrasound and MRI examinations were not possible and lung metastasis were not evaluable with conventional X-ray. Complete blood counts including differentiation were then repeated every 2 weeks, and biochemical tests were done every 4 weeks. 1 treatment cycle was defined as a 4 -week treatment. The DCEMRI procedure was repeated after 1 cycle. The first regular clinical staging was performed after 3 cycles with all methods necessary for response evaluation including the MRI and DCE-MRI. Thereafter, tumor staging was performed after every 3 rd cycle, in the case of clinical signs of progression earlier. Treatment was administered as follows: celecoxib $400 \mathrm{mg}$ twice daily continuously and capecitabine $500 \mathrm{mg}$ twice daily continuously. The drugs were given in the morning and $12 \mathrm{~h}$ later.
Table 2. Hematological and non-hematological toxicity (National Cancer Institute Common Toxicity Criteria, version 2.0 )

\begin{tabular}{lrrll}
\hline \multirow{2}{*}{ Toxicity } & \multicolumn{2}{l}{ Patients, $\mathrm{n}$} & & \\
\cline { 2 - 5 } & Grade 1 & Grade 2 & Grade 3 & Grade 4 \\
\hline Leucopenia & 0 & 1 & 0 & 0 \\
Thrombocytopenia & 3 & 0 & 0 & 0 \\
Anemia & 8 & 15 & 2 & 0 \\
Aspartat aminotransferase & 5 & 6 & 2 & 0 \\
Alanine aminotransferase & 12 & 2 & 1 & 0 \\
Nausea/vomiting & 14 & 3 & 0 & 1 \\
Dyspepsia/dysphagia & 5 & 2 & 0 & 0 \\
Hand-foot syndrome & 3 & 1 & 0 & 0 \\
Dry skin & 2 & 1 & 0 & 0 \\
Conjunctivitis & 5 & 0 & 0 & 0 \\
Cardiovascular events & 1 & 0 & 0 & 0 \\
Bleeding & 1 & 0 & 0 & 0 \\
Fatigue & 10 & 1 & 1 & 0 \\
\hline
\end{tabular}

\section{Biometric Analysis}

The primary endpoint was stable disease (SD) after 3 treatment cycles. Secondary endpoints were the documentation of antiangiogenic effects measured by DCE-MRI, time to progression (TTP), overall survival (OS) and the evaluation of drug-induced toxicity. TTP and OS curves were calculated according to the use of Kaplan-Meier method using standard software.

\section{Results}

37 patients were enrolled, 21 male, 16 female. Median age was 60 years, range 32-78. 12 patients had metastatic colorectal cancer, 10 advanced renal cell carcinoma, 2 gallbladder cancer, 2 cholangiocellular cancer, 3 pancreatic cancer, and 8 various other tumors. The patient characteristics are depicted in table 1. All patients had confirmed PD at the time of inclusion. 35 patients completed at least 1 treatment cycle. 2 patients dropped out during the first 4 weeks because of rapid PD, therapy was stopped and best supportive care was provided. All patients were evaluable for toxicity. Hematological toxicity was negligible: 15 patients grade 2, 2 patients grade 3 anemia; no episodes of leukopenia or thrombocytopenia $>$ grade 1 were observed. No treatment interruptions or dose reductions were necessary. 1 cardiovascular event with atrial fibrillation and 1 bleeding episode with hemoptysis were documented, both grade 1. Hematological and non-hematological toxicities (according to CTC catalogue version 2.0) are summarized in table 2 .

20 of 37 patients reached the first regular tumor evaluation point after 3 cycles of treatment. 17 (46\%) patients dropped out due to PD within the first 3 cycles. 9 patients had tumor progression after the 3 rd cycle. Thus, in summary, 26 of 37 had PD within 3 months. 11 patients were treated for more than 3 cycles $(4 \times$ renal cell cancer, $5 \times$ gastrointestinal cancer, 1 non-small cell lung cancer, and 1 cancer of unknown pri- 
Table 3. Response to treatment and TTP

\begin{tabular}{lc}
\hline Response & Patients, $\mathrm{n}(\%)$ \\
\hline Evaluable patients & $35 / 37(95)$ \\
Non-evaluable patients & $2 / 37(5)$ \\
Stable disease & $11 / 35(34)$ \\
Progressive disease & $24 / 35(66)$ \\
Mean TTP, weeks (range) & $15(2-56)$
\end{tabular}

TTP $=$ Time to progression

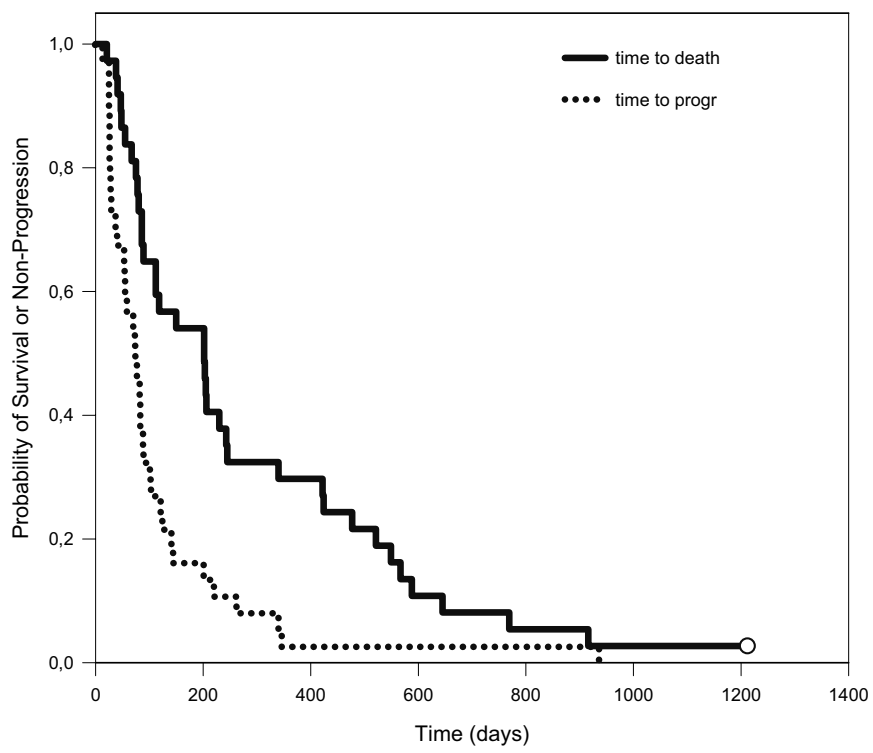

Fig. 1. Overall survival of all patients and time on study (solid line $=$ overall survival curve; dashed line $=$ time to progression).
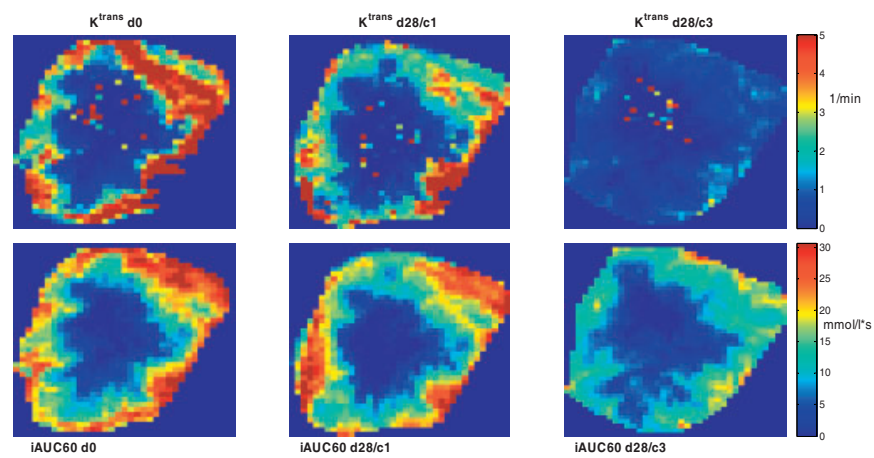

Fig. 2. $\mathrm{K}^{\text {trans }}$ and iAUC60 maps of patient 12 . A significant reduction in $\mathrm{K}^{\text {trans }}$, particularly in the tumor rim, is observed at the end of cycle 3 .

mary). Of those patients, 6 had 5-FU in the treatments before, and 5 patients never got this drug. All of these 11 patients had PD within 1 year of treatment, except for 1 patient with renal cell cancer who was 32 months on treatment before he progressed. The response to treatment using the RECIST criteria and TTP are summarized in table 3 . The OS and TTP curves of the whole patient group are shown in figure 1.
Fig. 3. Mean percentage change of $\mathrm{K}^{\text {trans }}$ for patients with progressive disease (PD) and stable disease (SD) at the end of cycles 1 and 3 .

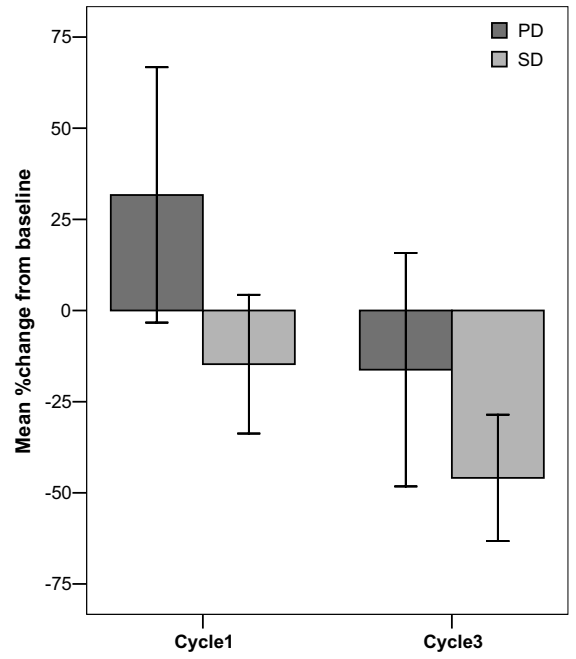

34 patients were included in the final DCE-MRI data analysis. 1 patient with SD was excluded from the analysis since no contrast agent uptake could be observed in the target lesion. The $\mathrm{K}^{\text {trans }}$ time profiles do not reveal a clear picture of a difference in response to therapy for the patients with either PD or SD. A reduction of more than $40 \%$ (which is considered as significant) in $\mathrm{K}^{\text {trans }}$ was seen in individual patients at the end of cycle 3. These patients had SD. An example of a pixelwise generated $\mathrm{K}^{\text {trans }}$ map for a patient with SD at the end of cycle 3 is represented in figure 2. A significant reduction in $\mathrm{K}^{\text {trans }}$, particularly in the tumor rim, is observed at the end of cycle 3. The mean percentage change of $\mathrm{K}^{\text {trans }}$ from baseline is presented in figure 3 for the patients with PD and SD at the end of cycle 1 and cycle 3 . Error bars mark the $90 \%$ confidence interval of the mean value. Patients with PD show an average increase of $41.8 \%$ in $\mathrm{K}^{\text {trans }}$ at the end of cycle 1 , whereas patients with SD show a reduction of $14.7 \%$. A mean reduction of $16.2 \%$ is observed in the patients $(n=5)$ with PD at the end of cycle 3 , and of $34.2 \%$ in the patients with SD indicating an antiangiogenic response to metronomic therapy. A minor reduction of $16 \%$ of $\mathrm{K}^{\text {trans }}$ is not sufficient to slow down tumor growth. SD was only observed with greater changes of $\mathrm{K}^{\text {trans }}$

\section{Discussion}

In general, the tolerability of the drug combination capecitabin and celecoxib was good. No drug-related serious adverse effects (SAE) were observed. Hospitalization due to medical reasons other than study drug-related were the most frequent reason for SAE reports. No serious cardiac problems were observed. Most of the patients felt comfortable with the used drug dosages possibly also due to the anti-inflammatory and anti-analgetic effects of celecoxib. Nearly $30 \%$ of all patients had stabilization of tumor growth after 12 weeks. These were patients with renal cell cancer and cancer from the gas- 
trointestinal tract. However, the majority of patients had no clinical benefit because tumor growth was too fast. We did not see any remissions which can be explained by the fact that pre-existing vessels may not be affected by the metronomic therapy. Thus, tumor growth can only be inhibited in the region with new vessels but not in the region of pre-existing vessels, so a significant tumor reduction can not be expected. These results indicate that for rapid tumor growth intermittent MTD-based cytotoxic therapy is necessary. The combination of metronomic and intermittent chemotherapy, as suggested [31] and successfully used in animal models [32], would be a merger of both types of anticancer treatment and should be considered for phase I and II evaluations. DCE-MRI allows tracking of changes in the tumor perfusion and the vessel permeability induced by antiangiogenic therapy. The DCEMRI results, expressed as $\mathrm{K}^{\text {trans }}$ or iAUC60 reduction in comparison to baseline as a surrogate for blood flow and vessel permeability [33], have shown that this metronomic therapy is indeed able to reduce these 2 parameters indicating that the concept is valid. Patients with early progression after 1 treatment cycle showed an increase in $\mathrm{K}^{\text {trans }}$. Interestingly, patients who had received 3 cycles of therapy and had PD according to the RECIST criteria showed a small reduction of $\mathrm{K}^{\text {trans }}$ which was less than the mean in the group with SD. This points to an effect of the therapy in these patients on blood flow and vessel permeability, which is, however, not strong enough to slow down or induce a stop of tumor growth. Cumulative experience from $>1,000$ DCE-MRI measurements in the past 7 years indicates that only a significant decrease in $\mathrm{K}^{\text {trans }}(40 \%$ or more) is able to slow down or stop further tumor growth. Use of the same DCE-MRI technology in clinical trials with specific tyrosine kinase inhibitors of the VEGF-receptor system resulted in higher reductions of the $\mathrm{K}^{\text {trans }}$ and iAUC60 in those patients judged as 'responder' [30, 34, 35].

Many new agents have been developed to inhibit specific pathways of angiogenesis, and some of these drugs such as bevacizumab, sunitinib, and sorafenib are now approved. Alternatively, inhibition of angiogenesis may be achieved with some approved 'old' drugs as well [25, 36-38]. Metronomic dosing means that continuously small amounts of the drug are present in the central compartment, acting at sites where action is useful for stopping tumor growth. A major target of an antiangiogenic therapy are the proliferating ECs of tumor vessels. Many of the cytotoxic drugs in use are given intravenously with a rapid fade from the central compartment, but there is a remarkable list of drugs which are available for metronomic schedules where the drugs are given orally over long periods of time at a much lower dose compared to intermittent intravenous application. These drugs are: treosulfan, trofosfamide, cyclofosfamide, vepesid, capecitabine, thiotepa, temozolamid, methotrexate, idarubicin, and topotecan. Not all of these drugs are available in such low dosages that a daily continuous administration is possible. A metronomic schedule of a cyctotoxic drug should guarantee sufficient drug concentrations at each moment for the inhibition of the target cells which are the proliferating ECs of the tumor vessels. Capecitabine is approved for a schedule with $2 \times 1,250 \mathrm{mg} / \mathrm{m}^{2} /$ day for 14 days with 7 days off which is approximately $4,500 \mathrm{mg} /$ day. From clinical experience it is known that a significant number of patients develop a severe hand-foot syndrome, and therefore a rest period has to be offered to reach full recovery. Additionally, a dose reduction has to be considered when therapy is restarted to avoid this type of toxicity. Clinical experience in our department in the past has shown that the dose of capecitabine had to be reduced in some patients to very low amounts ( $1 / 5$ of the full dose) without compromising the antitumor effect. This clinical observation as well as the laboratory data that have shown that the sensitivity of proliferating ECs to cytostatic agents is much higher than the sensitivity of TCs (5-100-fold) led to the development of the treatment protocol using capecitabine at a fixed continuously low daily dose $(2 \times 500 \mathrm{mg}$ which is nearly $1 / 5$ of the normal dose) together with celecoxib at a daily dose of $2 \times 400 \mathrm{mg}$, a drug with antiangiogenic properties [18]. The proliferating ECs are the first to be reached when the drugs under study enter the central compartment. Because TP - the activating enzyme necessary for the generation of 5-FU - is still present in the proliferating ECs, significant amounts of 5-FU can act in the ECs thereby stopping proliferation in this cell population. Whether this low drug amount is also able to inhibit proliferating TCs, is unknown and cannot be ruled out. The reason for combining a COX-2 inhibitor such as celecox$\mathrm{ib}$ with the above-mentioned therapy is based on preclinical data showing that COX-2 mediates the production of prostaglandin $E_{2}$ in epithelial tissues, resulting in an activation of signaling pathways that promote cell proliferation and inhibit cell death [39]. However, the influence of a metronomic therapy on tumor growth is probably much smaller than a cytostatic MTD-driven antitumor therapy. Ongoing tumor growth is still possible because the non-proliferating ECs of still existing vessels are unaffected but further tumor growth should be slowed down until a new balance is reached. Nevertheless, there is enough time and space to improve the results of metronomic schedules because the truly new antiangiogenic drugs are still under development. Optimization of metronomic therapies featuring antiangiogenic properties is possible with other combinations of cytotoxic and non-cytotoxic drugs (with angiogenic effects) including rapamycin [12], pioglitazone [15], cyclooxygenase-2 [17], arsenic [40], cannabinoids [41]), and zoledronic acid [42], all described as having antiangiogenic properties too. Even the combination of multitargeted signal transduction inhibitors (some are already approved), metronomic low-dose as well as MTD-driven cytotoxic regimens are in discussion [36]. Several metronomic studies have been published. In a series of combinations of pioglitazone, rofecoxib, and trofosfamide in melanoma/sarcoma [43], malignant vascular tumors [44], and kaposi sarcoma [45], tumor regressions and stabilization have been described. In a 
series of studies, celecoxib was combined with infusional 5-FU in advanced pancreatic cancer [46] and other tumors [25]. Low-dose metronomic methotrexate and cyclophosphamide were evaluated in breast cancer with encouraging results [47]. Rofecoxib and low-dose treosulfan were tested in a pilot study in melanoma patients [48], and metronomic low-dose cyclophosphamide in combination with dexamethasone was used in a trial with prostate cancer patients [49]. In a phase I trial, the combination of celecoxib with erlotinib was assessed in patients with non-small cell lung cancer, also with encouraging results [50].

The main criticism with respect to all published studies is still the low patient number and the use as 'last' line treatment in- stead of best supportive care. In general, the tolerability of metronomic therapies was reported as very acceptable. Most importantly, metronomic approaches need to demonstrate that they are better than best supportive care thus the length of a SD period and the quality of life reached are important endpoints of such studies.

\section{Acknowledgement}

The study was supported partly (organization, administration, documentation) by a restricted grant from Pfizer Inc. to K.M. We thank Ms. Stephan and Ms. Angerer for the great engagement in organization and documentation of the study.

\section{References}

1 Wenzel DG, Cosma GN: A model system for measuring comparative toxicities of cardiotoxic drugs for cultured rat heart myocytes, endothelial cells, and fibroblasts. Toxicology 1985;33:117-128.

$>2$ Browder T, Butterfield CE, Kraling BM, et al.: Antiangiogenic scheduling of chemotherapy improves efficacy against experimental drug-resistant cancer. Cancer Res 2000;60:1878-1886.

3 Paz K, Zhu Z: Development of angiogenesis inhibitors to vascular endothelial growth factor receptor 2. Current status and future perspective. Front Biosci 2005;10:1415-1439.

4 Hicklin DJ, Ellis LM: Role of the vascular endothelial growth factor pathway in tumor growth and angiogenesis. J Clin Oncol 2005;23:1011-1027.

$\checkmark 5$ Clement MK: Antiangiogenic potential of camptothecin and topotecan. Cancer Chemother Pharmacol 1999;44:411-416.

6 O'Leary JJ, Shapiro RL, Ren JJ, et al.: Antiangiogenic effects of camptothecin analogues 9-amino20(S)-camptothecin, topotecan and CPT-11 studies in the mouse cornea model. Clin Cancer Res 1999; 5:181-187.

7 Vacca A, Iurlaro M, Ribatti D, et al.: Antiangiogenesis is produced by noncytotoxic doses of vinblastin. Blood 1999;94:4143-4155.

8 Presta M, Rusnati M, Belleri M, et al.: Purine analogue 6-methylmercaptopurine riboside inhibits early and late phases of the angiogenesis process. Cancer Res 1999;59:2417-2424.

9 Klement G, Baruchel S, Rak J, Man S, Clark K, Hicklin DJ, Bohlen P, Kerbel RS: Continuous lowdose therapy with vinblastine and VEGF receptor2 antibody induces sustained tumor regression without overt toxicity. J Clin Invest 2000;8:15-24.

10 Sterba J, Valik D, Mudry P, Kepak T, Pavelka Z, Bajciova V, Zitterbart K, Kadlecova V, Mazanek P: Combined biodifferentiating and antiangiogenic oral metronomic therapy is feasible and effective in relapsed solid tumors in children: single-center pilot study. Onkologie 2006;29:308-313.

11 Baruchel S, Stempak D: Low-dose metronomic chemotherapy: myth or truth? Onkologie 2006;29: 305-307.

12 Guba M, von Breitenbach P, Steinbauer M, Köhl G, Flegel S, Hornung M, Bruns CJ, Zülke C, Farkas S, Anthuber KW, Jauch KW, Geissler EK: Rapamycin inhibits primary and metastatic tumor growth by anti-angiogenesis: involvement of vascular endothelial growth factor. Nat Med 2002;8:128-135.
13 Butzal M, Loges S, Schweizer M, Fischer U, Gehling UM, Hossfeld DK, Fiedler W: Rapamycin inhibits proliferation and differentiation of human endothelial cells. Exp Cell Res 2004;300:65-71.

14 Panigraphy D, Singer S, Shen LQ, Butterfield CE, Freedman DA, Chen EJ, Moses MA, Kilroy S, Dünsing S, Fletcher C, Fletcher JA, Hlatky L, Hahnfeldt P, Folkman J, Kaipainen A: PPAR $\gamma$ ligands inhibit primary tumor growth and metastasis by inhibiting angiogenesis. J Clin Invest 2002;110:923932.

15 Grommes C, Landreth GE, Heneka MT: Antineoplatic effects of peroxisome proliferator-activated receptor $\gamma$ agonists. Lancet Oncol 2004;5:419-429.

16 Graaf MR, Richel DJ, van Noorden CJF, Guchelaar HJ: Effects of statin and farnesyltransferase inhibitors on the development and progression of cancer. Cancer Treatm Rev 2004;30:609641.

17 Gasparini G, Longo R, Sarmiento R, Morabito A: Inhibitors of cyclo-oxygenase 2: a new class of anticancer agents? Lancet Oncol 2003;4:605-615.

18 Leahy KM, Ornberg RL, Wang Y, et al.: Cyclooxygenase- 2 inhibition by celecoxib reduces proliferation and induces apoptosis in angiogenic endothelial cells in vivo. Cancer Res 2002:62:625-631.

19 Masferrer JL, Leahy KM, Koki AT, et al.: Antiangiogenic and antitumor activities of cyclo-oxygenase-2 inhibitors. Cancer Res 2000;60:1306-1311.

20 Voutsadakis IA: Pathogenesis of colorectal carcinoma and therapeutic implications: the roles of the ubiquitin-proteasome system and COX-2. J Cell Mol Med 2007;2:252-285.

21 Steinbach G, Lynch PM, Phillips RK, et al.: The effect of celecoxib, a cyclo-oxygenase- 2 inhibitor, in familial adenomatous polyposis. New Eng J Med 2000; 342: 1946-1952.

22 Trifan OC, Durham WF, Salazar VS, et al.: COX-2 inhibition with celecoxib enhances antitumor efficacy and reduces diarrhea side effects of CPT-11. Cancer Res 2002:62:5778-5784.

23 Altorki NK, Keresztes RS, Port JL, Libby DM, Korst RJ, Flieder DB, Ferrara CA, Yankelevitz DF, Subbaramaiah K, Pasmatier MW, Dannenberg AJ: Celecoxib, a selectice cyclo-oxygenase-2 inhibitor, enhances the response to preoperative paclitaxel and carboplatin in early stage non-small-cell lung cancer. J Clin Oncol 2003;21:2645-2650.
24 Drevs J, Fakler J, Eisele S, Medinger M, Bing G, Esser N, Marme D, Unger C: Antiangiogenic potency of various chemotherapeutic drugs for metronomic chemotherapy. Anticancer Res 2004;24:1759-1764.

25 Kerbel RS, Kamen BA: The anti-angiogenic basis of metronomic chemotherapy. Nat Rev Cancer 2004:4:423-436.

26 Toi M, Rahman MA, Bando H, Chow LW: Thymidine phosphorylase in cancer biology and treatment. Lancet Oncol 2005:6:158-166.

27 De Vos FYFL, Willemse PHB, de Vries EGE, Gietema JA: Endothelial cell effects of cytotoxics: balance between desired and unwanted effects. Cancer Treatm Rev 2004;30:495-513.

28 Moghaddam A, Zhng HA, Fan TPD, Hut DE, Lees VC, Turleys H, Fox SB, Gatter KC, Harris AL, Bicknell R: Thymidine phosphorylase is angiogenic and promotes tumor growth. Proc Natl Acad Sci 1995;92:998-1002.

29 Ishitsuka H: Capecitabine: preclinical pharmacology studies. Invest New Drugs 2000;18:343-354.

30 Morgan B, Thomas AL, Ball H, Hennig J, Büchert M, Drevs J, Jivian A, Horsefield M, Mross K, Henry A, Peng B, Fuxius S, Unger C, O'Byrne K, Cherryman $G$, Laurent $D$, Dugan $M$, Steward WP Dynamic contrast enhanced magnetic resonance imaging as a surrogate marker for efficacy of the VEGF inhibitor PTK787/ZK 222584 (PTK/ZK) in patients with liver metastasis from colorectal cancer: phase I trial. J Clin Oncol 2003;21:3374-3338.

31 Mross K: Intermittent plus metronomic dosing (IMD) of cytotoxic agents: damage to the tumor cells and collateral damage to the tumor vasculature. Int J Clin Pharm Ther 2001;39:89-90.

32 Pietras K, Hanahan D: A multitargeted, metronomic, and maximum-tolerated dose 'chemoswitch' regimen is antiangiogenic, producing objective responses and survival benefit in a mouse model. J Clin Oncol 2005;23:939-952.

33 Strecker R, Scheffler K, Büchert M, Mross K, Drevs J, Hennig J: DCE-MRI in clinical trials: data acquisition and analysis methods. Int J Clin Pharm Ther 2003;41:603-606.

34 Mross K, Drevs J, Müller M, Medinger M, Marme D, Hennig J, Morgan B, Lebwohl D, Masson E, Ho YY, Günther C, Laurent D, Unger C: Phase I clinical and pharmacokinetic study of PTK/ZK, a multiple VEGF receptor inhibitor, in patients with liver metastasis from solid tumors. Eur J Cancer 2005; 41:1291-1299. 
35 Drevs J, Siegert P, Medinger M, Mross K, Strecker R, Zirrgiebel U, Harder J, Blum H, Robertson J, Jürgensmeier JM, Puchalski TA, Young H, Saunders O, Unger C: Phase I clinical study of AZD 2171, a oral vascular endothelial growth factor signaling inhibitor, in patients with advanced solid tumors. J Clin Oncol 2007;25:3045-3054.

36 Mross K: Antiangiogenesis therapy: concepts and importance of dosing schedules in clinical trials. Drug Resist Updat 2000;3:223-235.

37 Mross K: Angiogeneseinhibition in der Onkologie. Bremen-London-Boston, Uni-Med Science Verlag, 2007.

38 Kerbel RS, Viloria-Petit A, Klement G, Rak J: Accidental anti-angiogenic drugs anti-oncogene directed signal transduction inhibitors and conventional chemotherapeutic agents as example. Eur J Cancer 2000;36:1248-1259.

39 Raut CP, Nawrocki S, Lashinger LM, Davis DW, Khanbolooki S, Xiong H, Ellis LM, McConkey DJ: Celecoxib inhibits angiogenesis by inducing endothelial cell apoptosis in human pancreatic tumor xenografts. Cancer Biol Ther 2004;3: $1217-1224$.

40 Roboz GJ, Dias S, Lam G, Lane WJ, Soignet SL, Warrell RP, Rafii S: Arsenic trioxide induces dose- and time-dependent apoptosis of endothelium and may exert an antileukemic effect via inhibition of angiogenesis. Blood 2000;96: $1525-1530$.

41 Blazquez C, Gonzales-Feria L, Alvarez L, Haro A, Casanova ML, Guzman M: Cannabinoids inhibit the vascular endothelial growth factor pathway in gliomas. Cancer Res 2004;64:5617-5623.

42 Santini D, Vincenzi B, Dicuonzo G, Avvisati G, Massacesi C, Battistoni F, Gavasci M, Rocci L, Tirindelli MC, Altomare V, Tocchini M, Bonsignori M, Tonini G: Zoldronic acid induces significant and long-lasting modifications of circulating angiogenic factors in cancer patients. Clin Cancer Res 2003;9:2893-2897.

43 Reichle A, Bross K, Vogt T, Bataille F, Wild P, Berand A, Krause SW, Andreesen R: Pioglitazone and rofecoxib combined with angiostatically scheduled trofosfamide in the treatment of far-advanced melanoma and soft tissue sarcoma. Cancer 2004;101:2247-2256.

44 Vogt T, Hafner C, Bross K, Bataille F, Jauch KW, Berand A, Lanthaler M, Andreesen R, Reichle A: Antiangigenetic therapy with pioglitazone, rofecoxib, and metronomic trofosfamide in patients with advanced malignant vascular tumors. Cancer 2003;98:2251-2256.

45 Coras B, Hafner C, Reichle A, Hohenleutner U, Szeimies RM, Landthaler M, Vogt T: Antiangiogenic therapy with pioglitazone, rofecoxib, and trofosfamide in a patient with endemic Kaposi sarcoma. Arch Dermatol 2004;140:1504-1507.

46 Milella M, Gelibter A, Di Cosimo S, Bria E, Ruggeri EM, Carlini P, Malaguti P Pellicciotta M, Terzoli E, Cognetti F: Pilot study of celecoxib and infusional 5fluorouracil as second-line treatment for advanced pancreatic carcinoma. Cancer 2004;101:133-138

47 Colleoni M, Rocca A, Sandri MT, Zorzino L, Masci G, Nole F, Peruzzotti G, Robertson C, Orlando L, Cinieri S, de Braud F, Vuiale G, Goldhirsch A: Lowdose oral methotrexate and cyclophosphamide in metastatic breast cancer: antitumor activity and correlation with vascular endothelial factor levels. Ann Oncol 2002;13:73-80

48 Spieth K, Kaufmann R, Gille J: Metronomic oral low-dose treosulfan chemotherapy combined with cyclooxygenase- 2 inhibitor in pretreated advanced melanoma: a pilot study. Cancer Chemother Pharmacol 2003:52:377-382.

49 Glode LM, Barqawi A, Crighton F, Crawford ED, Kerbel R: Metronomic therapy with cyclophosphamide and dexamethasone for prostate carcinoma. Cancer 2003;98:1643-1648.

-50 Reckamp KL, Krysan K, Morrow JD, Milne GL, Newman RA, Tucker C, Elashoff RM, Dubinett SM, Figlin RA: A phase I trial to determine the optimal biological dose of celecoxib when combined with erlotinib in advanced nonsmall cell lung cancer. Clin Cancer Res 2006;12:3381-3388. 